\title{
Choanal atresia-hearing loss-cardiac defects-craniofacial dysmorphism syndrome
}

INSERM

\section{Source}

INSERM. (1999). Orphanet: an online rare disease and orphan drug data base. Choanal atresia-hearing loss-cardiac defects-craniofacial dysmorphism syndrome. ORPHA:1200

Choanal atresia - deafness - cardiac defects - dysmorphism syndrome, also known as Burn-McKeown syndrome, is an extremely rare multiple congenital anomaly syndrome characterized by bilateral choanal atresia (see this term) associated with a characteristic cranio-facial dysmorphism (hypertelorism with narrow palpebral fissures, coloboma of inferior eyelid (see this term) with presence of eyelashes medial to the defect, prominent nasal bridge, thin lips, prominent ears), that can be accompanied by hearing loss, unilateral cleft lip, preauricular tags, cardiac septal defects and anomalies of the kidneys. The features of this syndrome overlaps considerably with those of the CHARGE syndrome (see this term). 